\title{
Transient right ventricular dysfunction caused by retractor during lower hemisternotomy mitral valve repair in a patient with pectus excavatum
}

\author{
Homare Okamura, MD, ${ }^{\mathrm{a}}$ Jon Parmet, $\mathrm{MD},{ }^{\mathrm{b}}$ and Robert S. Farivar, MD, PhD, ${ }^{\mathrm{a}}$ Philadelphia, Pa
}

We report a case of the right ventricular (RV) dysfunction caused by compression of the RV by retractor after mitral valve repair through a lower hemisternotomy in a patient with pectus excavatum.

\section{CLINICAL SUMMARY}

A 45-year-old woman with a history of pectus excavatum was referred to our hospital for severe symptomatic mitral valve insufficiency. She weighed $50 \mathrm{~kg}$ and was $155 \mathrm{~cm}$ tall. Echocardiography revealed severe symptomatic mitral valve regurgitation caused by prolapse of the anterior leaflet. Left ventricular ejection fraction was preserved.

Mitral valve repair was performed through a lower hemisternotomy, which extended into the second intercostal space on the right. A Koros Baxter retractor (Koros USA, Inc, Moorpark, Calif) was used. Pericardial stay sutures were placed to elevate the right side of the heart for exposure. Cardiopulmonary bypass (CPB) was established with cannulation of the ascending aorta and the femoral vein. Antegrade and retrograde cardioplegia were used according to our routine. Exposure of the mitral valve was accomplished through the interatrial (Sondergaard) groove. The mitral valve was repaired with a $36-\mathrm{mm}$ complete annuloplasty ring.

Approximately 10 minutes into weaning from $\mathrm{CPB}$, we noted on transesophageal echocardiography that the chest retractor was compressing the RV (Figure 1, $A$ and $B$ ). We removed the right-sided pericardial stay sutures to allow the heart to relax into the pericardial well.

The patient had moderate to severe RV dysfunction develop during weaning from $\mathrm{CPB}$. Her tricuspid regurgitation went from minimal to moderate. There was no left-sided heart failure. Despite RV dysfunction, she was weaned from CPB without any device but with inotropic support. Aortic crossclamp time was 52 minutes, and total CPB time was 87

\footnotetext{
From the Division of Cardiovascular Surgery, ${ }^{\text {a }}$ Department of Surgery, University of Pennsylvania School of Medicine, Philadelphia, Pa; and the Department of Anesthesiology, ${ }^{\mathrm{b}}$ Pennsylvania Hospital, Philadelphia, Pa.

Disclosures: Authors have nothing to disclose with regard to commercial support.

Received for publication July 31, 2013; revisions received Aug 12, 2013; accepted for publication Aug 22, 2013; available ahead of print Oct 29, 2013.

Address for reprints: Robert S. Farivar, MD, PhD, University of Pennsylvania, Cardiothoracic Surgery, 301 S 8th St, 4B, Philadelphia, PA 19072 (E-mail:

Robert.farivar@uphs.upenn.edu).

J Thorac Cardiovasc Surg 2014;147:e3-5

$0022-5223 / \$ 36.00$

Copyright (C) 2014 by The American Association for Thoracic Surgery

http://dx.doi.org/10.1016/j.jtcvs.2013.08.068
}

minutes. The patient was transferred to the critical care unit with inotropic support, where she was extubated on postoperative day 1. Transesophageal echocardiography revealed RV dysfunction (Figure 2, A). During the course of 1 week, the RV contraction gradually improved, and inotropes were tapered (Figure 2, B). The patient's tricuspid regurgitation also normalized, and she was discharged home on postoperative day 13. She continues to do well with no mitral or tricuspid regurgitation 6 months after surgery.

\section{DISCUSSION}

This case illustrates an unexpected complication of minimally invasive cardiac surgery in a patient with pectus excavatum. Surgeons have increasingly adopted minimally invasive cardiac surgery because of shorter hospital stay, better cosmesis, and equal short- and long-term outcomes to full sternotomy operations. ${ }^{1,2}$ Operation in restricted spaces may potentially cause inadvertent complications, however, especially in patients with anatomic deformity.

Pectus excavatum is the most common congenital deformity of the chest wall, with a prevalence of 1 in 400 births, and is characterized by an inward displacement of the sternum. ${ }^{3}$ The posteriorly depressed sternum displaces the heart in the left chest cavity and can compromise exercise tolerance and cardiac function. ${ }^{4,5}$

In this case, intraoperative transesophageal echocardiography before operation showed no obvious RV dysfunction; however, the retractor placed in the hemisternotomy incision compressed the RV during the weaning from $\mathrm{CPB}$ after the repair. The compression may have interfered with right coronary blood flow, caused prolonged ischemia of the right side of the heart, and subsequently led to the RV dysfunction. Postoperatively, RV dysfunction continued with the need for inotropic support for nearly 1 week. Other possible causes of intraoperative and postoperative RV dysfunction include insufficient myocardial protection, pulmonary embolism, myocardial infarction of the right coronary artery, and left-sided heart failure.

Myocardial protection by retrograde cardioplegia can potentially result in a poor distribution of cardioplegia to the right side of the heart. Because, however, the coronary sinus perfusion pressure was normal, the operation was rapid, and no electrical activity of the myocardium was detected during $\mathrm{CPB}$, insufficient myocardial protection is 

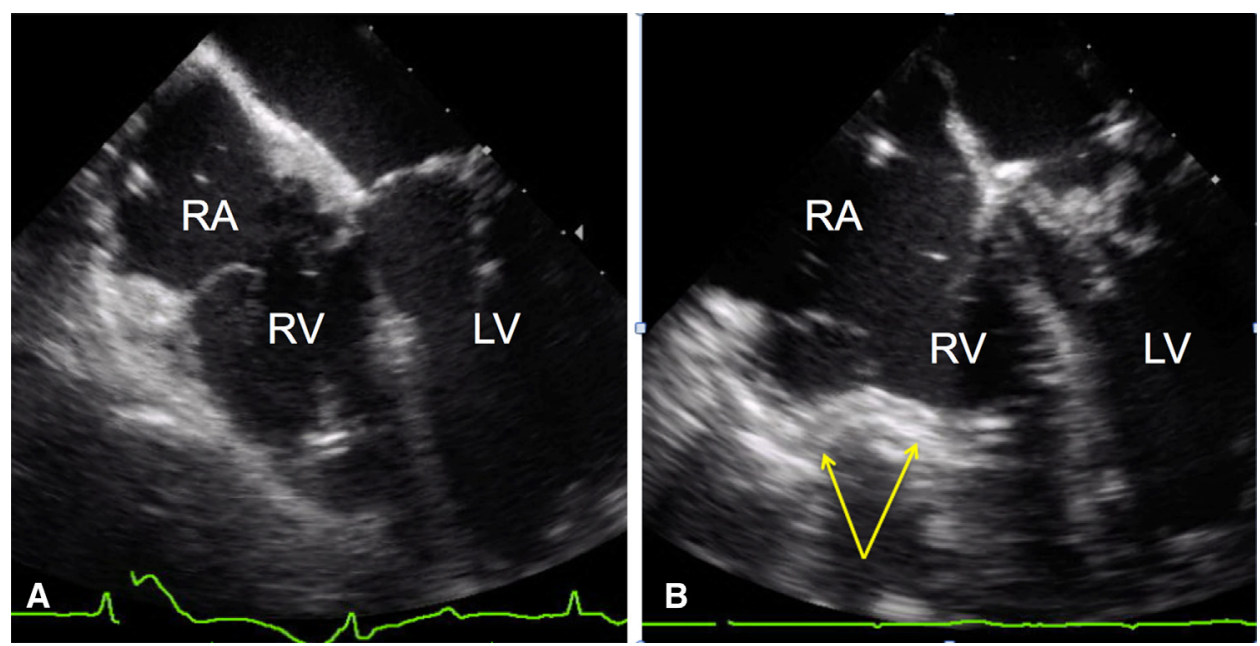

FIGURE 1. Intraoperative transesophageal echocardiography focusing on the right ventricle. A, The image before surgery shows neither right ventricular dysfunction nor compression of the heart. B, On the image during weaning from cardiopulmonary bypass, the retractor is compressing the right ventricle (spanned by arrows). $R A$, Right atrium; $R V$, right ventricle; $L V$, left ventricle.
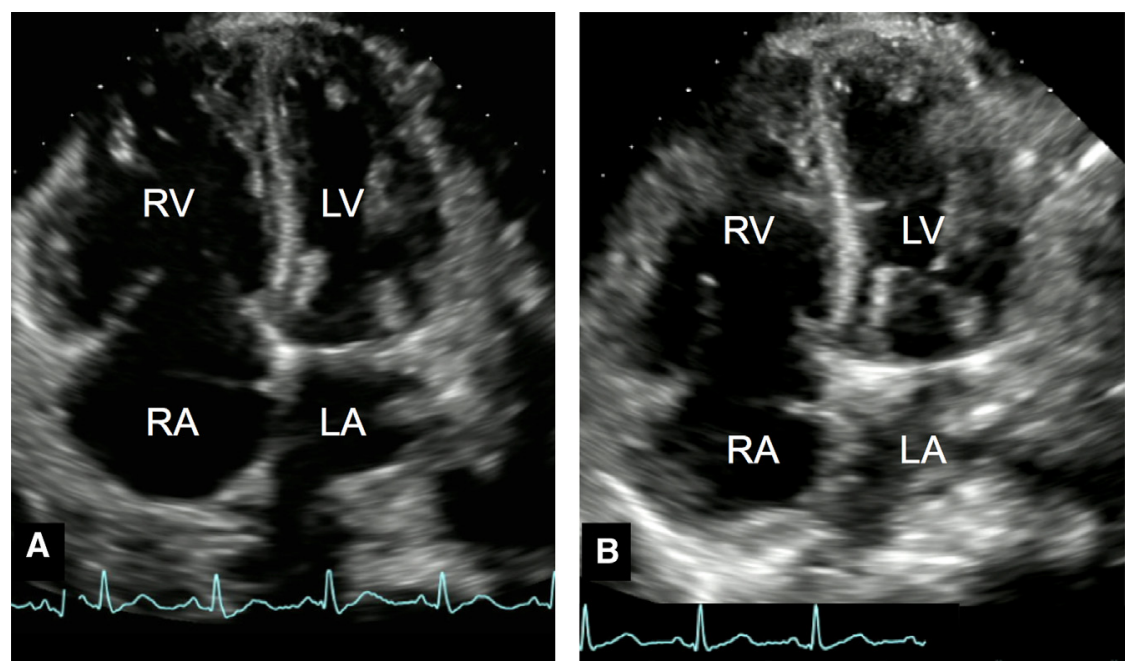

FIGURE 2. Postoperative transthoracic echocardiography. A, On postoperative day 2, the right ventricle was severely enlarged as a result of the right ventricular dysfunction. B, On postoperative day 8 , right ventricular function was restored and the dimension of the right ventricle decreased. $R A$, Right atrium; $R V$, right ventricle; $L A$, left atrium; $L V$, left ventricle.

unlikely. In addition, because we saw the retractor compress the RV on transesophageal echocardiography (Figure 1,B), we consider this to be the primary cause. Other possible causes described are also less likely, because the left ventricle contracted well postoperatively and RV function was restored in time with only inotropic support.

\section{CONCLUSIONS}

We present to our knowledge the only report of RV dysfunction during lower hemisternotomy caused by a retractor. This was compounded by minimally invasive cardiac surgery in a patient with pectus excavatum. Care should be taken to avoid this complication in patients with lower hemisternotomy during surgery by loosening pericardial stay sutures when terminating $\mathrm{CPB}$ or by instead performing a full sternotomy.

\section{References}

1. Iribarne A, Russo MJ, Easterwood R, Hong KN, Yang J, Cheema FH, et al. Minimally invasive versus sternotomy approach for mitral valve surgery: a propensity analysis. Ann Thorac Surg. 2010;90:1471-7; discussion 1477-8.

2. Goldstone AB, Atluri P, Szeto WY, Trubelja A, Howard JL, MacArthur JW Jr, et al. Minimally invasive approach provides at least equivalent results for surgical correction of mitral regurgitation: a propensity-matched comparison. J Thorac Cardiovasc Surg. 2013;145:748-56.

3. Jaroszewski D, Notrica D, McMahon L, Steidley DE, Deschamps C. Current management of pectus excavatum: a review and update of therapy and treatment recommendations. J Am Board Fam Med. 2010;23:230-9. 
4. Krueger T, Chassot PG, Christodoulou M, Cheng C, Ris HB, Magnusson L. Cardiac function assessed by transesophageal echocardiography during pectus excavatum repair. Ann Thorac Surg. 2010;89:240-3.
5. Lesbo M, Tang M, Nielsen HH, Frøkiær J, Lundorf E, Pilegaard HK, et al Compromised cardiac function in exercising teenagers with pectus excavatum. Interact Cardiovasc Thorac Surg. 2011;13:377-80.

\title{
Delayed esophageal diverticulum formation after stent-based treatment of perforation
}

\author{
Meghana R. Kunkala, MD, and Claude Deschamps, MD, Rochester, Minn
}

Epiphrenic diverticula are rare. Presenting symptoms often include dysphagia, regurgitation, chest pain, and heartburn. Intermittent episodes of aspiration, mostly nocturnal, are not uncommon. ${ }^{1}$ Some diverticula, however, are completely asymptomatic or present with minimal symptoms. In a series of 112 patients with diverticula, $42 \%$ were completely free of symptoms. ${ }^{2}$

The etiology of these diverticula is greatly debated. Most are pulsion pseudodiverticula and are thought to be secondary to an increase in intraesophageal pressure. An associated motility disorder is often present. In fact, Tedesco and colleagues ${ }^{1}$ found that 17 of 21 patients presenting with diverticula had an associated motility disorder, such as achalasia, diffuse esophageal spasm, or a nonspecific esophageal motility disorder. Surgical treatment is offered on the basis of the presence of symptoms and resulting complications and often includes a myotomy to address the motility disorder. ${ }^{3}$

Diverticula formation after esophageal perforation, specifically after esophageal perforation treated with stent placement, has not previously been reported in the literature. The vast majority of esophageal perforations have been treated surgically. In select cases, however, selfexpanding stents have been introduced into the management of patients with esophageal perforations, with mixed outcomes. ${ }^{4-6}$ A meta-analysis of 75 studies shows a $14.8 \%$ pooled mortality for spontaneous perforations, with stenting associated with lower mortality $(7.3 \%)$, although this is likely biased by patient selection. ${ }^{5}$ Serious complications, such as respiratory insufficiency, mediastinal emphysema, ulceration secondary to stents, and migration of stents, have all been reported in patients undergoing stent placement for symptomatic management of esophageal

From the Division of Thoracic Surgery, Mayo Clinic, Rochester, Minn.

Disclosures: Authors have nothing to disclose with regard to commercial support.

Received for publication July 12, 2013; revisions received Aug 22, 2013; accepted for publication Aug 29, 2013; available ahead of print Oct 21, 2013.

Address for reprints: Claude Deschamps, MD, Division of Thoracic Surgery, Department of Surgery, Mayo Building 12W, Mayo Clinic, 200 First St SW, Rochester,

MN 55905 (E-mail: deschamps.claude@ mayo.edu).

J Thorac Cardiovasc Surg 2014;147:e5-8

$0022-5223 / \$ 36.00$

Copyright (C) 2014 by The American Association for Thoracic Surgery

http://dx.doi.org/10.1016/j.jtcvs.2013.08.077

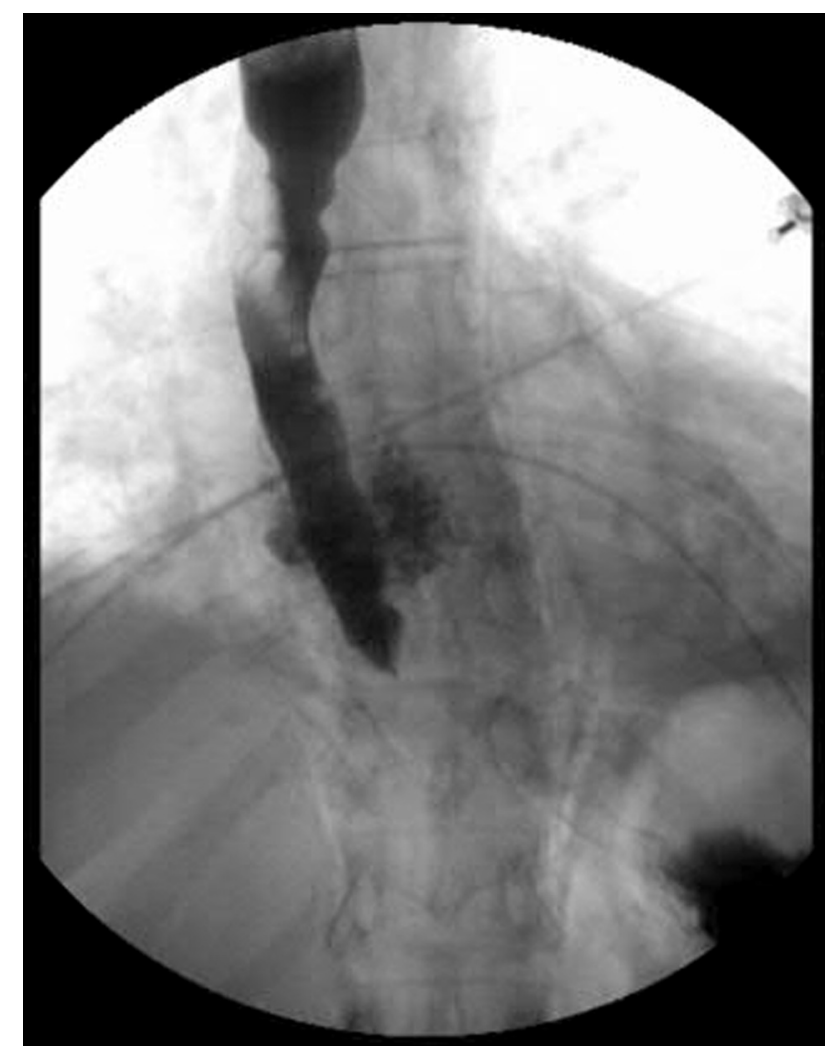

FIGURE 1. Initial esophagogram demonstrating distal esophageal perforation.

cancer. $^{7}$ No studies to date, however, have analyzed midterm to long-term complications of stent management of spontaneous esophageal perforation. We present a case of delayed esophageal diverticula formation after spontaneous esophageal perforation managed with stent placement.

\section{CLINICAL SUMMARY}

An 82-year-old woman was seen at an outside institution with abrupt onset of left upper quadrant abdominal pain after ingestion of a cup of coffee. The pain radiated to her back. A computed tomographic scan was obtained and showed a pneumomediastinum; this prompted an esophagogram, which showed evidence of a distal esophageal perforation and normal motility of the 